\title{
Caracterização sensorial de néctares de tamarindo (Tamarindus indica L.) adoçados com xilitol
}

\author{
Sensorial characterization of tamarindo nectars (Tamarindus indica L.) sweetened with xylitol \\ Caracterización sensorial de néctares de tamarindo (Tamarindus indica L.) endulzados con xilitol
}

Recebido: 13/01/2021 | Revisado: 16/01/2021 | Aceito: 17/01/2021 | Publicado: 19/01/2021

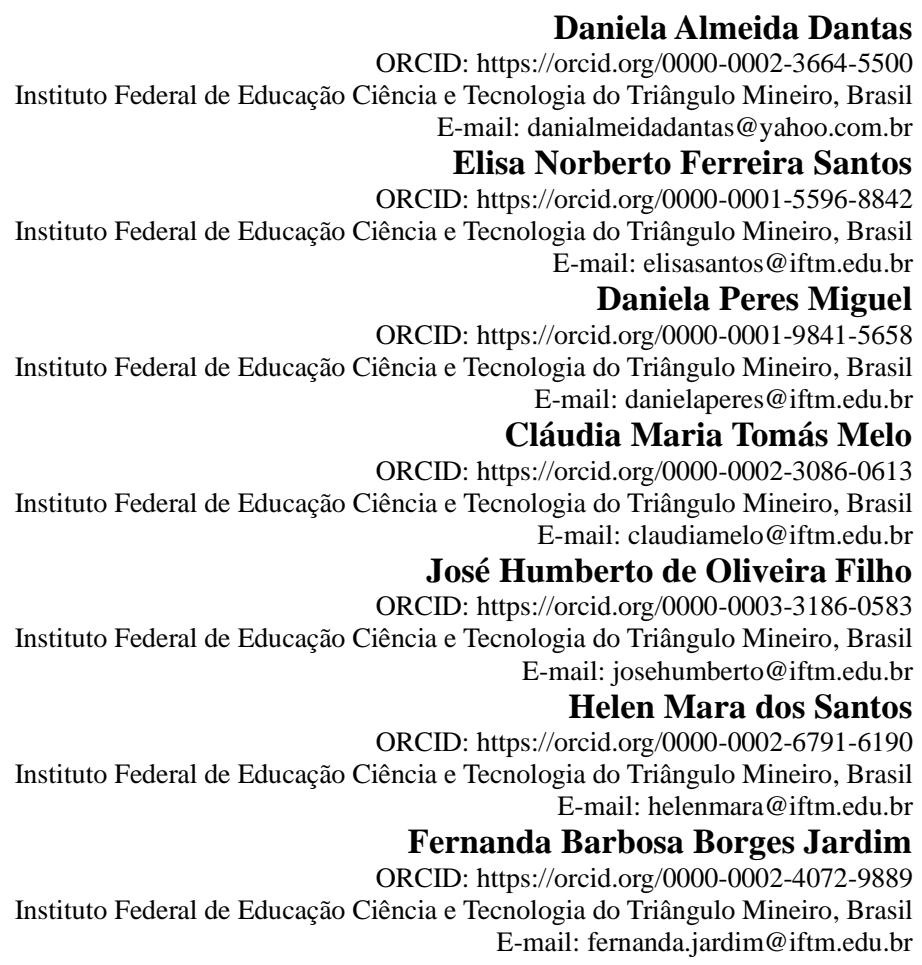

\section{Resumo}

Este trabalho teve como objetivo desenvolver e avaliar sensorialmente a formulação ideal de néctar de tamarindo adoçado com xilitol. Os frutos de tamarindo foram obtidos de fazendas de Araguari, Minas Gerais, processados e avaliados conformes os parâmetros físico-químicos previstos na legislação. A partir da polpa, foram elaboradas formulações de néctares com diferentes concentrações de polpa de tamarindo: 20\% (T20), 22\% (T22), 24\% (T24) e $26 \%$ (T26) e realizadas análises físico-químicas e sensoriais (diluição ideal). Posteriormente, formulações de néctares com a proporção de polpa considerada ideal no teste sensorial de diluição foram elaboradas com diferentes concentrações de xilitol: 11\% (T11), 12\% (T12) e 13\% (T13) e realizadas análises físico-químicas e sensoriais (doçura ideal). Os resultados físico-químicos das polpas e néctares foram conformes os padrões de identidade e qualidade de polpa e suco de tamarindo, com exceção dos resultados de acidez total dos néctares, visto que não há padrão de identidade e qualidade para néctar de tamarindo, o que pode explicar estas diferenças. $\mathrm{O}$ teste sensorial de diluição ideal foi realizado por 106 consumidores e estes indicaram as amostras T24 e T26 como as ideais em termos de diluição. No teste sensorial de doçura ideal, aplicado para 101 consumidores, estes indicaram que as formulações controle (12\% de açúcar) e T13 foram as ideais. A formulação ideal de néctar de tamarindo foi a constituída de $24 \%$ de polpa e $13 \%$ de xilitol.

Palavras-chave: Néctar; Tamarindo; Polióis; Sensorial.

\section{Abstract}

This work aimed to develop sensorial evaluation of the ideal formulation of tamarind nectar sweetened with xylitol. Tamarind fruits from farms in the region of Araguari, Minas Gerais, Brazil, processed and evaluated according to the physical-chemical parameters provided for in the legislation. From the pulp, nectars formulations with different concentrations of tamarind pulp were prepared: 20\% (T20), 22\% (T22), 24\% (T24) and 26\% (T26) and then physical- 
chemical, and sensory analyses (Ideal dilution) were performed. Subsequently, formulations of nectars were prepared with ideal proportion of pulp, with different concentrations of xylitol: 11\% (T11), 12\% (T12) and 13\% (T13) and then performed physicochemical and sensorial analyses (Ideal sweetness). The physicochemical results from pulp and nectars were consistent with the identity and quality standards of pulp and juice of tamarind, with the exception of the results of total acidity of the nectars, since there is no standard of identity and quality for nectar of tamarind, which can may explain these differences. 106 consumers carried out the sensory test of ideal dilution and they indicated samples T24 and T26 as ideal in terms of dilution. In the sensory test of ideal sweetness, applied to 101 consumers, they indicated that the control (12\% sugar) and T13 formulations were ideal. The ideal formulation of tamarind nectar consisted of $24 \%$ pulp and $13 \%$ xylitol.

Keywords: Nectar; Tamarind; Polyols; Sensory.

\section{Resumen}

Este trabajo tuvo como objetivo desarrollar y evaluar sensorialmente la formulación ideal de néctar de tamarindo endulzado com xilitol. Los frutos de tamarindo precedían de granjas de Araguari, Minas Gerais, procesados y evaluados según los parámetros físico-químicos previstos en la legislación. A partir de la pulpa se elaboraron formulaciones de néctares com diferentes concentraciones de pulpa de tamarindo: 20\% (T20), 22\% (T22), 24\% (T24) y $26 \%$ (T26) y se realizaron análisis físico-químicos y sensoriales (dilución óptima). Posteriormente, se realizaron formulaciones de néctares com la proporción de pulpa considerada ideal en la prueba de dilución sensorial con diferentes concentraciones de xilitol: 11\% (T11), 12\% (T12) y 13\% (T13) y se realizaron análisis físico-químicos y sensoriales (dulzura ideal). Los resultados físico-químicos de las pulpas e néctares estuvieron de acuerdo con los estándares de identidad y calidad de la pulpa y jugo de tamarindo, con excepción de los resultados de acidez total de los néctares, ya que no existe um stándar de identidad y calidad para el néctar de tamarindo, el cual puede explicar estas diferencias. La prueba sensorial de dilución ideal fue realizada por 106 consumidores e indicaron las muestras T24 y T26 como ideales en términos de dilución. En la prueba sensorial de dulzura ideal, aplicada a 101 consumidores, indicaron que las formulaciones de control (12\% de azúcar) y T13 eran ideales. La formulación ideal de néctar de tamarindo consistía en $24 \%$ de pulpa y $13 \%$ de xilitol.

Palabras clave: Néctar; Tamarindo; Polioles; Sensorial.

\section{Introdução}

A preocupação atual com o bem-estar e consumo regular de frutas e hortaliças está presente na população, considerando inclusive a recomendação de seu consumo para a saúde. Conforme pesquisa recente de Vigitel, do Ministério da Saúde em 2018, mostra que ocorreu aumento de 15,5\% na aquisição de hortaliças e de frutas nos últimos dez anos, concentrado entre as mulheres, cerca de 27,2\%, e em nome da adoção de "hábitos mais saudáveis". (Anuário Brasileiro, 2019).

Entre as dez atividades que apontaram expansão na produção em 2019, tem-se as bebidas no geral com 4\%. A categoria de bebidas não alcoólicas, como exemplo os néctares, segue em expansão também. A fabricação de bebidas não alcoólicas teve crescimento de 3,2\% em 2019, dado apoiado pela elevação de 10,6\% no último mês deste ano. O volume de vendas cresceu 2,4\% no ano de 2016 (5,8 bilhões de litros) e totalizou praticamente 6 bilhões de litros em 2017. A previsão é que chegará a 6,5 bilhões em 2021, conforme informações da Associação Brasileira de Supermercados (ABRAS, 2017; 2020).

Conforme o Decreto $n^{\circ} 6.871$ (Brasil, 2009), em seu artigo 21, néctar é a bebida não fermentada, obtida da diluição em água potável da parte comestível do vegetal ou de seu extrato, adicionado de açúcares, destinada ao consumo direto.

Os frutos nativos ou cultivados no cerrado possuem características sensoriais únicas, com ênfase nos atributos cor, aroma e sabor, além de considerável valor nutricional devido ao conteúdo de fibras alimentares, vitaminas e minerais. O cerrado possui recursos naturais renováveis e grande variedade de espécies frutíferas nativas e cultivadas com características singulares, como por exemplo, o tamarindo (Schiassi et al., 2018).

O tamarindo (Tamarindus indica L.) pertence à família Fabaceae, sendo uma espécie arbórea, que é cultivada em praticamente todo o território brasileiro. A polpa é utilizada em condimentos e molhos e também é consumida na forma de bebidas não alcoólicas. O fruto é rico em aminoácidos, ácidos graxos, minerais e apresenta elevado conteúdo de vitamina C. O aroma característico e sabor ácido-doce (agridoce) são devidos a uma combinação de altos teores de ácido tartárico e redução de açúcares (Caluwé, Halamova \& Damme, 2010; Tabela Brasileira de Composição de Alimentos - TACO, 2011; Flora do Brasil, 2019). Apesar de a polpa ser encontrada nas gôndolas de supermercado, não há oferta de néctares de tamarindo em 
nível nacional.

O tamarindo é um fruto sazonal, portanto, normalmente, é consumido na forma processada (polpas, geleias, molhos). A oferta de um néctar de tamarindo adicionado de um adoçante natural, como o xilitol, é uma opção saudável interessante para o perfil de consumidor atual, em substituição aos néctares adicionados de açúcares e adoçantes artificiais.

$\mathrm{O}$ xilitol $\left(\mathrm{C}_{5} \mathrm{H}_{12} \mathrm{O}_{5}\right)$ é um açúcar-álcool penta-hidroxilado, que pode estar em pequenas quantidades em algumas frutas e verduras. É usado em alimentos processados como substituto da sacarose para diabéticos e outros públicos com restrição ou ingestão controlada de açúcares, uma vez que seu metabolismo é independente de insulina. Na indústria farmacêutica, é aplicado como agente anticariogênico e para reduzir risco de otite média (Albuquerque et al., 2014). No entanto, seu efeito sensorial em néctares de frutas ainda não foi plenamente elucidado.

Neste contexto, o objetivo do presente estudo foi desenvolver e caracterizar sensorialmente formulações de néctares de tamarindo com diferentes concentrações de xilitol.

\section{Metodologia}

O estudo realizado foi de natureza quantitativa e experimental. Houve a coleta de dados físico-químicos por meio de análises laboratoriais de amostras de polpa e néctares de tamarindo e aplicação de questionários a consumidores para medição de atributos sensoriais. Os resultados foram tratados por análise estatística (Pereira et al., 2018).

\subsection{Produção e caracterização físico-química da polpa de tamarindo}

Frutos de tamarindo foram colhidos em fazendas na região da cidade de Araguari-MG, entre agosto e setembro de 2019. Conforme metodologia adaptada por Cardoso et al. (2012), a polpa de tamarindo foi obtida a partir da imersão dos frutos em água potável na proporção de 1:4 (v/v) por 2 horas. Posteriormente, a polpa foi separada do pericarpo e sementes por meio de peneira para uso alimentício de 14 a 16 mesh, através de fricção manual. A polpa obtida foi homogeneizada em liquidificador doméstico (Arno) por 1 minuto, acondicionada em embalagem de polietileno de alta densidade (500 g) e submetida à pasteurização nas condições de $90^{\circ} \mathrm{C}$ por 2 minutos em banho-maria. Em seguida, as polpas embaladas foram resfriadas em banho de gelo até temperatura ambiente e acondicionadas em freezer a $-20 \pm 2^{\circ} \mathrm{C}$ até a utilização.

Foram realizadas análises físico-químicas da polpa de tamarindo no Laboratório de Bromatologia do IFTM, Campus Uberlândia, em triplicata, segundo metodologia do Instituto Adolfo Lutz - IAL (2008). Foram determinados os sólidos


( $\left(100 \mathrm{~g}^{-1}\right.$ ), conforme exigências da legislação, Instrução Normativa n. 37 de 01 de outubro de 2018, que estabelece os padrões de identidade e qualidade da polpa de tamarindo (Brasil, 2018).

\subsection{Processamento e caracterização físico-química e sensorial dos néctares de tamarindo (Diluição Ideal)}

Para a determinação da diluição ideal dos néctares de tamarindo, foram preparadas quatro formulações da bebida. O processamento dos néctares foi realizado na planta de processamento de vegetais do IFTM, Campus Uberaba. As matérias primas utilizadas na elaboração dos néctares foram: açúcar refinado Kehdi®; água mineral Mineiro® e polpa de tamarindo preparada conforme tópico 2.1 .

Os néctares foram produzidos utilizando uma formulação padrão (12\% de açúcar), estabelecida conforme pré-testes de bancada. As demais formulações variaram em relação à proporção de polpa e de acordo com a Instrução Normativa n. 12 de 04 de setembro de 2003 (Brasil, 2003), que estabelece que o néctar, cuja quantidade mínima da polpa de fruta ou do suco de fruta ou de vegetal não tenha sido fixada em Regulamento Técnico específico, não deve ser inferior a $20 \%$ (m/m), no caso de vegetal com acidez muito elevada ou sabor muito forte (Tabela 1). 
Tabela 1. Formulações de néctares de tamarindo com variação no teor de polpa, considerando um quantitativo de 3.500 g de bebida para cada formulação.

\begin{tabular}{|c|c|c|c|c|}
\hline \multirow[t]{2}{*}{ Ingredientes } & \multicolumn{4}{|c|}{ Formulações de néctar } \\
\hline & T20 & T22 & T24 & T26 \\
\hline Polpa (g) & $700(20 \%)$ & $770(22 \%)$ & $840(24 \%)$ & $910(26 \%)$ \\
\hline Açúcar Refinado (g) & $420(12 \%)$ & $420(12 \%)$ & $420(12 \%)$ & $420(12 \%)$ \\
\hline Água Mineral (g) & $2380(68 \%)$ & $2310(66 \%)$ & $2240(64 \%)$ & $2170(62 \%)$ \\
\hline
\end{tabular}

T20= Néctar com $20 \%$ de polpa; T22= Néctar com $22 \%$ de polpa; T24= Néctar com $24 \%$ de polpa; T26= Néctar com 26\% de polpa. Fonte: Adaptada de Deliza (2001).

Os procedimentos efetuados na produção do néctar foram similares aos realizados por Souza et al. (2019) em que os ingredientes foram adicionados em liquidificador industrial para homogeneização por dois minutos. Após a mistura, os néctares foram disponibilizados em garrafas de vidro de $500 \mathrm{~mL}$ com tampa no formato de rolha. Estas garrafas foram previamente esterilizadas em água sob ebulição. Então os néctares foram levados para a pasteurização em banho maria a $65^{\circ} \mathrm{C}$ por 10 minutos. Após a pasteurização, procedeu-se ao resfriamento das garrafas de vidro em recipiente com banho de gelo, até temperatura ambiente (entre 27 e $25^{\circ} \mathrm{C}$ ). $\mathrm{O}$ produto pronto foi acondicionado em câmara fria a $7^{\circ} \mathrm{C} \pm 1^{\circ} \mathrm{C}$, até sua utilização.

Foram realizadas análises físico-químicas dos néctares de tamarindo no Laboratório de Bromatologia do IFTM, Campus Uberlândia, em triplicata, segundo metodologia do IAL (2008). Os parâmetros analisados foram sólidos solúveis,

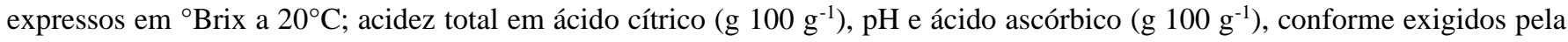
Instrução Normativa no 37 de 01 de outubro de 2018 (Brasil, 2018).

As análises sensoriais foram realizadas no laboratório de análise sensorial do IFTM, Campus Uberaba, com autorização prévia do Comitê de Ética da UFTM, conforme Parecer 3.532.635. O Termo de Consentimento Livre e Esclarecido (TCLE) para assinatura foram apresentados aos provadores, antes do início dos testes.

Os ensaios sensoriais foram realizados logo após as análises microbiológicas previstas pela legislação para néctares de tamarindo, coliformes a $35^{\circ} \mathrm{C}$, estando as bebidas aptas para consumo com contagem ausente. Para os ensaios de diluição ideal, foi adotada uma Escala do Ideal não estruturada, de $10 \mathrm{~cm}$, sendo o ponto âncora inferior correspondente a "extremamente mais diluído que o ideal", o ponto âncora superior "extremamente mais concentrado que o ideal" e o ponto central "ideal", conforme modelo adaptado de Teixeira (2011).

Os testes foram realizados empregando-se cabines individuais. As amostras foram servidas de forma monádica, em temperatura de refrigeração $\left(7^{\circ} \mathrm{C}\right)$, em recipientes descartáveis $(50 \mathrm{~mL})$, brancos, codificados com algarismos de três dígitos, oferecendo-se, entre uma amostra e outra, água para a limpeza dos palatos. Os consumidores receberam as quatro amostras de néctar de tamarindo, com diferentes proporções de polpa de tamarindo (20, 22, 24 e $26 \% \mathrm{v} / \mathrm{v})$. Os consumidores indicaram qual dos pontos da escala melhor descrevia sua opinião em relação à diluição das amostras. Participaram 106 consumidores não treinados, com faixa etária entre 18 e 50 anos, consumidores habituais de suco de fruta (Macfie et al., 1989).

As respostas dos provadores foram medidas por um único analista, sempre com a mesma régua plástica de $15 \mathrm{~cm}$. As medidas foram consideradas notas, variando de 0 a $10 \mathrm{~cm}$, com $5 \mathrm{~cm}$ correspondendo ao ponto "ideal". Os dados foram avaliados em blocos completos balanceados pela Análise de Variância (ANOVA) e sendo esta significativa, as médias foram comparadas pelo teste de Tukey, considerando o nível de significância de 5\% ( $\mathrm{p}<0,05)$, obtendo-se o valor de diluição considerado ideal pelos consumidores (Ferreira et al., 2000; Deliza, 2001). Foi realizado o teste de normalidade e 
homogeneidade pelos testes de Shapiro-Wilk e Oneillmathews e se caso não houvesse normalidade foi aplicado o Teste de Friedman com cálculo da mediana.

\subsection{Processamento e caracterização físico-química e sensorial dos néctares de tamarindo (Doçura Ideal)}

Para a determinação da doçura ideal dos néctares de tamarindo, foram preparadas quatro formulações da bebida. $\mathrm{O}$ processamento dos néctares foi realizado na planta de processamento de vegetais do IFTM, Campus Uberaba. As matérias primas utilizadas na elaboração dos néctares foram: açúcar refinado Kehdi®; água mineral Mineiro®, xilitol Mãe Natureza® e polpa de tamarindo preparada conforme tópico 2.1 .

Os néctares foram produzidos utilizando uma formulação padrão com uma proporção de $24 \%$ de polpa, estabelecida conforme resultados sensoriais do teste de diluição ideal, e teor padrão de açúcar de 12\%. As demais formulações substituíram o açúcar pelo xilitol em diferentes proporções (Tabela 2).

Tabela 2. Formulações de néctares de tamarindo com variações no teor de xilitol, considerando um quantitativo de $2.500 \mathrm{~g}$ de bebida para cada formulação.

Ingredientes $\quad$ Formulações de néctar

\begin{tabular}{ccccc}
\hline & C & T11 & T12 & T13 \\
\hline Polpa (g) & $600(24 \%)$ & $600(24 \%)$ & $600(24 \%)$ & $600(24 \%)$ \\
Açúcar Refinado (g) & $300(12 \%)$ & - & - & - \\
Xilitol (g) & - & $275(11 \%)$ & $300(12 \%)$ & $325(13 \%)$ \\
Água Mineral (g) & $1600(64 \%)$ & $1625(65 \%)$ & $1600(64 \%)$ & $1575(63 \%)$ \\
\hline
\end{tabular}

$\mathrm{C}=$ Néctar com $12 \%$ de sacarose; T11= Néctar com $11 \%$ de xilitol; T12= Néctar com 12\% de xilitol; T13= Néctar com $13 \%$ de xilitol. Fonte: Adaptado de Deliza (2001).

Os procedimentos realizados na produção dos néctares e as análises físico-químicas das formulações foram equivalentes aos descritos no tópico 2.2 .

As análises sensoriais foram realizadas no laboratório de análise sensorial do IFTM, Campus Uberaba, com autorização prévia do Comitê de Ética da UFTM, conforme Parecer 3.532.635. Foram apresentados aos provadores o Termo de Consentimento Livre e Esclarecido (TCLE) para assinatura, antes do início dos testes.

Os ensaios sensoriais foram realizados logo após as análises microbiológicas previstas pela legislação para néctares de tamarindo, coliformes a $35^{\circ} \mathrm{C}$, estando as bebidas aptas para consumo com contagem ausente. Para os ensaios de doçura ideal, foi utilizada uma Escala do Ideal não estruturada, de $10 \mathrm{~cm}$, sendo o ponto âncora inferior correspondente a "extremamente menos doce que o ideal", o ponto âncora superior "extremamente mais doce que o ideal" e o ponto central "ideal", conforme modelo adaptado de Teixeira (2011).

Os testes foram realizados empregando-se cabines individuais. As amostras foram servidas de forma monádica, em temperatura de refrigeração $\left(7^{\circ} \mathrm{C}\right)$, em recipientes descartáveis $(50 \mathrm{~mL})$, brancos, codificados com algarismos de três dígitos, oferecendo-se, entre uma amostra e outra, água para a limpeza dos palatos. Os consumidores receberam quatro amostras do néctar de tamarindo, a controle (12\% de sacarose) e com diferentes proporções de xilitol (11, 12 e $13 \%$ v/v). Os provadores indicaram qual dos pontos da escala melhor descrevia sua opinião em relação à doçura das amostras. Foram recrutados 101 
consumidores não treinados, consumidores habituais de suco de fruta (Macfie et al., 1989).

As respostas dos provadores foram medidas por um único analista, sempre com a mesma régua plástica de $15 \mathrm{~cm}$. As medidas foram consideradas notas, variando de 0 a $10 \mathrm{~cm}$, com $5 \mathrm{~cm}$ correspondendo ao ponto "ideal". Os dados foram avaliados em blocos completos balanceados pela Análise de Variância (ANOVA) e sendo esta significativa, as médias foram comparadas pelo teste de Tukey, considerando o nível de significância de 5\% ( $\mathrm{p}<0,05)$, obtendo-se o valor de doçura considerado ideal pelos provadores (Ferreira et al., 2000; Deliza, 2001). Foi realizado o teste de normalidade e homogeneidade pelos testes de Shapiro-Wilk e Oneillmathews e se caso não houvesse normalidade foi aplicado o Teste de Friedman com cálculo da mediana.

\section{Resultados e Discussão}

\subsection{Resultados físico-químicos da polpa de tamarindo}

Os resultados físico-químicos da polpa de tamarindo (Tabela 3) atenderam os requisitos mínimos previstos pelo Padrão de Identidade e qualidade de polpa de tamarindo.

Tabela 3. Resultados físico-químicos da polpa de tamarindo.

\begin{tabular}{|c|c|c|c|c|c|}
\hline Polpas & $\mathrm{pH}$ & ${ }^{\circ}$ Brix & $\begin{array}{c}\text { Acidez } \\
\text { (g ácido cítrico } 100 \mathrm{~g}^{-1} \text { ) }\end{array}$ & $\begin{array}{l}\text { Ácido Ascórbico } \\
\quad\left(\mathrm{mg} 100 \mathrm{~g}^{-1}\right)\end{array}$ & $\begin{array}{c}\text { Sólidos Totais } \\
(\%)\end{array}$ \\
\hline Média & 2,30 & 13,1 & 2,74 & 3,30 & 13,97 \\
\hline Padrão mínimo* & 2,3 & 6,0 & 1,9 & 0,1 & 6,5 \\
\hline
\end{tabular}

* Instrução Normativa n ${ }^{\circ} 37$ de 01 de outubro de 2018 (Brasil, 2018). Fonte: Autores.

O resultado médio de $\mathrm{pH}$ encontrado nas polpas de tamarindo foi baixo, típico de frutas com elevada acidez. O teor de sólidos solúveis e totais apresentaram resultados que corresponderam aproximadamente ao dobro estabelecido pelos padrões de identidade e qualidade. A acidez apresentou resultado próximo ao mínimo estabelecido e o teor de ácido ascórbico foi considerável, superior ao mínimo estabelecido pela legislação (Tabela 3). Esta variabilidade é normal, uma vez que é dependente de condições de cultivo do fruto, local de cultivo, condições ambientais de cultivo e espécie do fruto.

\subsection{Resultados físico-químicos e sensorial dos néctares de tamarindo (Diluição Ideal)}

Os resultados dos parâmetros físico-químicos dos néctares de tamarindo atenderam aos valores previstos pelos Padrões de Identidade e qualidade de suco de tamarindo, com exceção da acidez (Tabela 4).

Apesar do suco não se caracterizar como néctar, esta foi considerada a comparação mais próxima na legislação. Sabese que o suco é obtido sem diluição da polpa, diferentemente do néctar, que pode utilizar uma proporção mínima de $20 \%$ de polpa. Esta diferença de proporção de polpa pode explicar a acidez total menor dos néctares em comparação ao padrão para suco. 
Tabela 4. Resultados médios dos parâmetros físico-químicos dos néctares de tamarindo (diluição ideal).

\begin{tabular}{|c|c|c|c|c|}
\hline Tratamentos & $\mathrm{pH}$ & $\begin{array}{l}\text { Sólidos solúveis } \\
\qquad\left({ }^{\circ} \text { Brix }\right)\end{array}$ & $\begin{array}{l}\text { Acidez em ácido cítrico } \\
\qquad\left(\mathrm{g} 100 \mathrm{~mL}^{-1}\right)\end{array}$ & $\begin{array}{l}\text { Ácido Ascórbico } \\
\left(\mathrm{mg} 100 \mathrm{~mL}^{-1}\right)\end{array}$ \\
\hline $\mathrm{T} 20$ & 2,71 & 15,6 & 0,64 & 0,413 \\
\hline $\mathrm{T} 22$ & 2,67 & 15,6 & 0,65 & 0,455 \\
\hline $\mathrm{T} 24$ & 2,70 & 15,6 & 0,68 & 0,455 \\
\hline $\mathrm{T} 26$ & 2,67 & 16,2 & 0,75 & 0,496 \\
\hline Padrão mínimo* & 2,3 & 6,0 & 1,9 & 0,1 \\
\hline
\end{tabular}

* Instrução Normativa $n^{\circ} 37$ de 01 de outubro de 2018 (Brasil, 2018). T20= Néctar com 20\% de polpa; T22= Néctar com 22\% de polpa; T24= Néctar com $24 \%$ de polpa; T26= Néctar com $26 \%$ de polpa. Fonte: Autores.

Os resultados físico-químico dos néctares de tamarindo apresentaram a mesma tendência observada na polpa de tamarindo, ou seja, pH baixo, teores médios de sólidos solúveis pelo menos 2,5 vezes superiores e teores médio de ácido ascórbico pelo menos quatro vezes superiores aos padrões da legislação. Os néctares apresentaram resultados bem próximos para todos os parâmetros analisados, indicando que variações de $2 \%$ de polpa na formulação não afeta de forma significativa o perfil físico-químico das bebidas (Tabela 4).

$\mathrm{Na}$ avaliação dos resultados sensoriais de diluição ideal, houve normalidade e homogeneidade dos valores, verificados pelos testes de Shapiro-Wilk e Oneillmathews, respectivamente. Houve diferença entre os resultados sensoriais dos tratamentos pelo teste $\mathrm{F}(\mathrm{p}<0,05)$ conforme apresentado na Tabela 5.

Tabela 5. Valores médios obtidos no teste sensorial de diluição ideal para néctares de tamarindo com diferentes proporções de polpa.

\begin{tabular}{cc}
\hline Tratamentos & Média \pm Desvio Padrão \\
\hline T26 & $5,60 \pm 1,76 \mathrm{a}$ \\
T24 & $5,48 \pm 1,72 \mathrm{a}$ \\
T20 & $4,23 \pm 1,74 \mathrm{~b}$ \\
T22 & $4,13 \pm 1,57 \mathrm{~b}$ \\
\hline
\end{tabular}

a,b As médias seguidas de mesma letra não diferem entre si pelo teste de Tukey a 5\%. T20= Néctar com $20 \%$ de polpa; T22= Néctar com $22 \%$ de polpa; T24= Néctar com $24 \%$ de polpa; T26= Néctar com $26 \%$ de polpa. Fonte: Autores.

Os valores médios obtidos pelos tratamentos T26 e T24 não diferiram entre si, mas diferiram dos demais. Também, os valores médios obtidos pelos tratamentos T20 e T22 não diferiram entre si (Tabela 5). Logo, os tratamentos T24 e T26 obtiveram médias mais próximas do ideal, nota 5, considerando que T24 apresentou valor absoluto mais próximo do ideal. Pela curva de regressão linear (Figura 1), verifica-se, através da equação, que considerando o y = 5 (nota ideal), obtém-se uma diluição de $23,51 \%$, valor este mais próximo ao tratamento T24. 
Figura 1. Curva de Regressão Linear obtida no teste sensorial de diluição ideal para néctares de tamarindo com diferentes proporções de polpa.



Fonte: Autores.

Apesar do néctar de tamarindo ser uma bebida de elevada acidez quando comparada a outros néctares de frutos tropicais, os consumidores deste estudo consideraram as concentrações de polpa mais elevadas como as ideais em termos de diluição (Tabela 5 e Figura 1). Vale destacar que resultados obtidos por todas as formulações se aproximaram do considerado ideal (nota 5). Acredita-se que concentrações superiores a $26 \%$ não seriam adequadas, pelo aumento da percepção sensorial de acidez do fruto, o qual foi constatada em testes preliminares neste estudo. A legislação recomenda um mínimo de $20 \%$ de polpa no néctar de frutos com acidez muito elevada ou sabor muito forte (Brasil, 2003).

Os resultados foram similares aos encontrados por Bedetti et al. (2013), que avaliaram quatro formulações de néctar de cagaita variando o teor de polpa nas concentrações de 20\% (F20), 30\% (F30), 40\% (F40) e 50\% (F50). Levando em consideração os atributos cor, sabor e impressão global, os resultados das formulações F20 e F30 não diferiram entre si $(\mathrm{p}>0,05)$ para todos os atributos sensoriais avaliados e apresentaram aceitação significativamente menor que as formulações F40 e F50 (p<0,05).

Maeda et al. (2006) avaliaram o néctar da camu-camu, um fruto silvestre da Amazônia. O néctar foi obtido pela mistura da polpa, açúcar e água, ocorrendo variações de polpa e açúcar. As concentrações de polpa foram de 17, 20 e 25\%. A formulação ideal foi escolhida por meio de análise sensorial, empregando-se teste de preferência para um grupo de 30 provadores não treinados. Houve preferência $(43,75 \%)$ pela formulação com $17 \%$ de polpa.

Freitas (2013) avaliou a diluição ideal em néctar de pitanga em formulações com 25\%, 30\%, 35\%, 40\%, 45\% e 50\% de polpa. Utilizou-se a escala do ideal variando de - 4,5 a 4,5, sendo 0 o ponto central (ideal). Correlacionando a nota atribuída a cada concentração de polpa, aplicou-se regressão linear e chegou-se na concentração ideal de $24,4 \%$ de polpa atribuída pela reta. Porém, por legislação não se pode preparar o néctar de pitanga com concentração inferior à $25 \%$ de polpa, sendo esta então considerada a concentração ideal.

Silva et al. (2020) desenvolveram iogurte grego com adição de polpa de tamarindo com diferentes concentrações de polpa de tamarindo $(5 \%, 10 \%$ e $15 \%)$ e avaliaram sensorialmente o efeito destas diferentes concentrações. De acordo com o teste de ordenação-preferência, 43,90\% dos julgadores preferiram o tratamento com 5\% de polpa de tamarindo. Nesta pesquisa, diferentemente dos resultados obtidos pelos néctares de tamarindo do presente estudo, os julgadores optaram pela formulação de menor teor de polpa de tamarindo. 


\subsection{Resultados físico-químicos e sensorial dos néctares de tamarindo (Doçura Ideal)}

Os resultados dos parâmetros físico-químicos dos néctares de tamarindo ficaram de acordo com os valores previstos pelos Padrões de Identidade e qualidade de polpa e suco de tamarindo, com exceção da acidez (Tabela 6).

Este comportamento foi o mesmo dos resultados obtidos pelos néctares de tamarindo desenvolvidos para o teste de diluição ideal (tópico 3.2), ou seja, é esperada a acidez total menor dos néctares em comparação ao padrão para suco.

Tabela 6. Resultados médios dos parâmetros físico-químicos dos néctares de tamarindo (doçura ideal).

\begin{tabular}{|c|c|c|c|c|}
\hline Tratamentos & $\mathrm{pH}$ & $\begin{array}{l}\text { Sólidos solúveis } \\
\left({ }^{\circ} \text { Brix }\right)\end{array}$ & $\begin{array}{l}\text { Acidez em ácido cítrico } \\
\qquad\left(\mathrm{g} 100 \mathrm{~mL}^{-1}\right)\end{array}$ & $\begin{array}{l}\text { Ácido Ascórbico } \\
\left(\mathrm{mg} 100 \mathrm{~mL}^{-1}\right)\end{array}$ \\
\hline $\mathrm{C}$ & 2,82 & 15,97 & 0,71 & 0,610 \\
\hline T11 & 2,81 & 14,63 & 0,69 & 0,671 \\
\hline $\mathrm{T} 12$ & 2,91 & 14,83 & 0,66 & 0,610 \\
\hline $\mathrm{T} 13$ & 2,91 & 15,63 & 0,65 & 0,651 \\
\hline Padrão mínimo* & 2,3 & 6,0 & 1,9 & 0,1 \\
\hline
\end{tabular}

* Instrução Normativa $\mathrm{n}^{\circ} 37$ de 01 de outubro de 2018. C = Néctar com $12 \%$ de sacarose; $\mathrm{T} 11=$ Néctar com $11 \%$ de xilitol; T12= Néctar com 12\% de xilitol; T13= Néctar com 13\% de xilitol. Fonte: Autores.

Os resultados físico-químico dos néctares de tamarindo com xilitol apresentaram a mesma tendência observada nos néctares de tamarindo com diferentes proporções de polpa deste estudo. Os teores médios de pH foram baixos, os de sólidos solúveis pelo menos 2,4 vezes superiores e os teores médio de ácido ascórbico pelo menos seis vezes superiores aos padrões da legislação. As diferenças nas proporções do adoçante xilitol dos néctares não interferiu nos resultados físico-químicos, que foram próximos. Os resultados físico-químicos do néctar controle (com sacarose) em comparação com os néctares adoçados com xilitol também foram similares. A literatura é escassa de informações sobre néctares adoçados com polióis, especialmente o xilitol. (Tabela 6)

$\mathrm{Na}$ avaliação dos resultados sensoriais de doçura ideal, os resultados foram submetidos ao teste de normalidade e homogeneidade e não houve normalidade, portanto foi aplicado o Teste de Friedman, com cálculo da mediana (Tabela 7). Houve diferença entre os resultados sensoriais dos tratamentos pelo teste de Friedman a nível de significância de 5\%.

Tabela 7. Tabela das medianas aplicada aos resultados sensoriais (doçura ideal) dos néctares de tamarindo.

\begin{tabular}{cc}
\hline Tratamentos & Medianas \pm Desvio Padrão \\
\hline C & $5,00 \pm 1,81 \mathrm{a}$ \\
T13 & $5,00 \pm 1,85 \mathrm{a}$ \\
T11 & $4,15 \pm 1,84 \mathrm{~b}$ \\
T12 & $4,85 \pm 1,56 \mathrm{~b}$ \\
\hline
\end{tabular}

\footnotetext{
a, b As medianas seguidas de mesma letra não diferem entre si pelo teste de Friedman a 5\%. C = Néctar com 12\% de sacarose; T11= Néctar com $11 \%$ de xilitol; T12= Néctar com $12 \%$ de xilitol; T13= Néctar com $13 \%$ de xilitol. Fonte: Autores.

Os valores médios obtidos pelos tratamentos C e T13 não diferiram entre si, mas diferiram dos demais. Também, os valores médios obtidos pelos tratamentos T11 e T12 não diferiram entre si (Tabela 7).

Obteve-se nota média ideal de doçura no néctar com maior proporção de xilitol na formulação (T13), e o valor foi equivalente ao obtido pelo néctar controle (C). Pela curva de regressão linear (Figura 2), verifica-se, através da equação, que considerando o y = 5 (nota ideal), obtém-se uma doçura de 12,70, valor este também próximo ao tratamento T13.
} 
Figura 2. Curva de Regressão Linear obtida no teste sensorial de doçura ideal para néctares de tamarindo com diferentes proporções de xilitol.

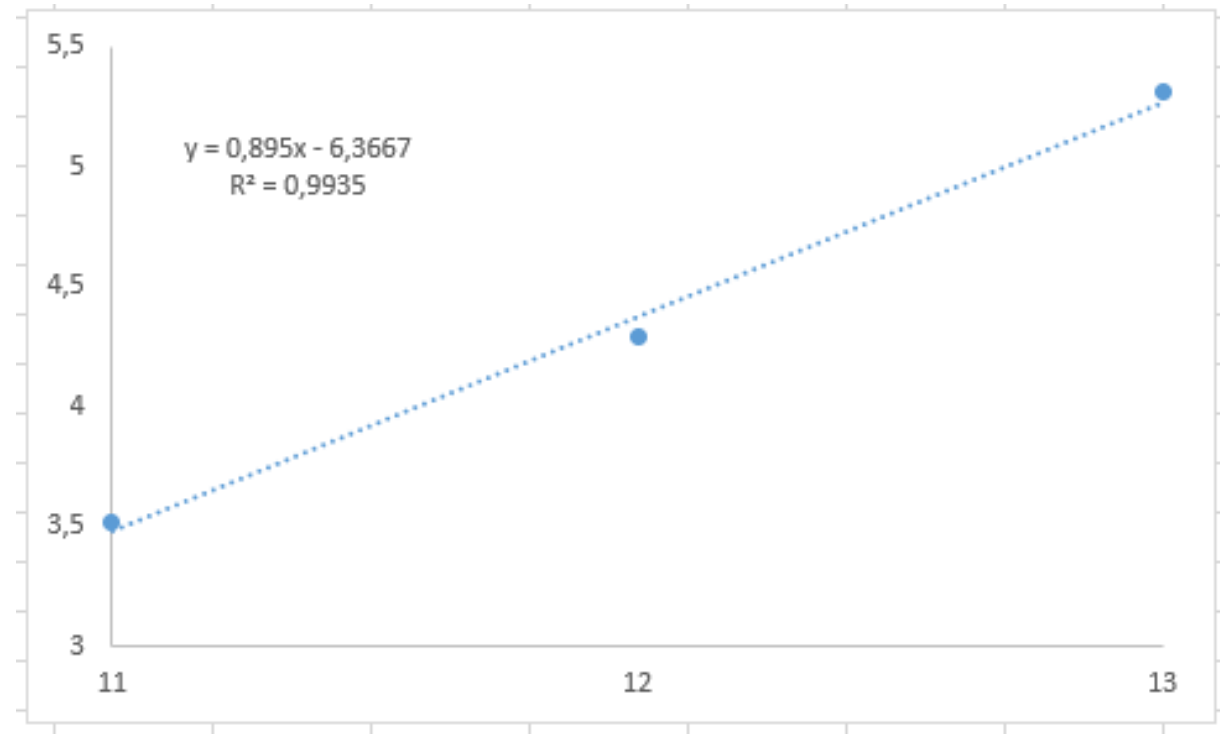

Fonte: Autores.

Considerando que o xilitol é um edulcorante com poder de doçura equivalente à sacarose, atestou-se que os consumidores perceberam esta equivalência ao considerar a formulação T13 a ideal. Também, constatou-se que as notas obtidas por todas as formulações com xilitol e pela formulação controle (com adição de sacarose) foram próximas (Tabela 7 e Figura 2). Estes resultados confirmam que o xilitol é um adoçante que não promove alterações sensoriais significativas, o que seria uma vantagem tecnológica frente a outros adoçantes, especialmente os artificiais. Considerando que o néctar de tamarindo necessita de uma adição considerável de sacarose em sua formulação, por se tratar de uma polpa com elevada acidez, a substituição parcial ou total da sacarose pelo xilitol pode ser uma opção saudável para o consumidor atual, que prefere a ingestão de alimentos com teores reduzidos de açúcares.

O xilitol possui o maior poder adoçante dentre todos os polióis, sendo o único com capacidade adoçante semelhante à da sacarose. O xilitol é bastante utilizado em alimentos como agente de "corpo", e em conjunto com outros edulcorantes pode atenuar o gosto residual destes ou apresentar efeitos sinérgicos de edulcoração (Cândido, Campos, 1996; Zacharis, 2012). Estas características também podem ter contribuído para a escolha dos consumidores.

Maia et al. (2008) realizaram a avaliação sensorial de sorvetes à base de xilitol. Preliminarmente, realizaram um teste com soluções de sacarose, comparativamente a soluções de xilitol nas mesmas concentrações (1; 2,5 e 5\%). Identificaram que na concentração de $1 \%$ não foi identificada diferença significativa em relação à amostra controle. Nas demais concentrações, foram identificadas diferenças. A explicação para estes resultados pode ser atribuída ao fato da solução não possuir nenhum tipo de sabor e/ou aroma. No presente estudo, pode-se inferir que houve equivalência para doçura entre os tratamentos com $13 \%$ de xilitol (T13) e controle (C), mas as concentrações de xilitol de T11 e T12 obtiveram notas menores para doçura ideal, ou seja, os consumidores identificaram diferenças de doçura para estas formulações, diferentemente de T13.

Maia et al. (2008) ainda aplicaram o teste triangular para detectar diferença sensorial relacionada à doçura. Os resultados mostraram diferenças sensoriais significativas $(\mathrm{p}<0,05)$ para todas as formulações (sabores: nata, morango e chocolate), exceto para as formulações de morango nas concentrações de $100 \%$ sacarose e 50\% xilitol, indicando que o sabor de morango, aliado à substituição de metade da quantidade de sacarose por xilitol, foi a formulação mais equilibrada. 
Yuyama et al. (2008) elaboraram geleias de cubiu com xilitol e com sacarose na proporção de 1:1 (polpa:xilitol e polpa:sacarose) que foram concentradas até a obtenção de $65^{\circ}$ Brix, com ajuste de $\mathrm{pH}$ e adição de pectina. As geleias foram avaliadas por meio de análises físico-química, microbiológica e sensorial, mensalmente, por um período de 180 dias. Identificaram na avaliação sensorial a aceitabilidade de 85,62\% para a geleia com xilitol e 81,05\% para geleia com sacarose, sem diferença significativa, em nível de 5\% de significância, confirmando a tendência de similaridade entre formulações com xilitol, em substituição à sacarose, assim como confirmado no presente estudo.

Não foi possível efetuar comparações dos néctares de tamarindo com outros autores, pela escassez de trabalhos disponíveis na literatura.

\section{Conclusão}

Quanto maior a proporção de polpa, mais próxima foi a nota considerada ideal nos néctares de tamarindo para o critério sensorial de diluição ideal. O néctar de tamarindo ideal foi o com teor de $24 \%$ de polpa, considerando que o néctar de tamarindo com $26 \%$ também apresentou resultado equivalente.

O néctar de tamarindo ideal para o critério sensorial doçura foi o com teor de $13 \%$ de xilitol, podendo esta formulação ser uma opção adequada para néctares de tamarindo isentos de adição de açúcares. Portanto, a formulação de néctar de tamarindo com melhores resultados sensoriais foi a constituída de $24 \%$ de polpa e $13 \%$ de xilitol.

São sugeridos futuros estudos sobre a viabilidade tecnológica e avaliação sensorial de néctares de tamarindo, uma vez que este fruto tropical apresenta potencial econômico no Brasil.

\section{Agradecimentos}

Agradecemos ao Instituto Federal de Educação Ciência e Tecnologia do Triângulo Mineiro (IFTM) e Coordenação de Aperfeiçoamento de Pessoal de Nível Superior (CAPES) pelo apoio à pesquisa de mestrado.

\section{Referências}

Albuquerque, T. L. de, Silva, I. J., Macedo, G. R., \& Rocha, M. V. P. (2014). Biotechnological production of xylitol from lignocellulosic wastes: A review. Process Biochemistry, 49 (11), 1779-1789. https://doi.org/10.1016/j.procbio.2014.07.010

Anuário Brasileiro de Horti\&Fruti/ Cleonice de Carvalho et al. (2019). Santa Cruz do Sul: Editora Gazeta, 100 p. http://www.editoragazeta.com.br/sitewp/wpcontent/uploads/2020/05/HORTIFRUTI_2020.pdf

Associação Brasileira de Supermercados - ABRAS. (2017). Boas Perspectivas para o mercado de sucos. http://www.abras.com.br/clipping.php?area=10\&clipping=63063

Associação Brasileira de Supermercados - ABRAS. (2020). Em ritmo oposto ao da indústria, produção de bebidas alcoólicas cresce 4,8\% em 2019. https://www.abras.com.br/clipping/bebidas/70083/em-ritmo-oposto-ao-da-industria-producao-de-bebidas-alcoolicas-cresce-4-8-em-2019

Bedetti, S. de F., Cardoso, L. de M., Santos, P. R. G., Dantas, M. I. de S., \& Sant'ana, H. M. P. (2013). Néctar de Cagaita (Eugenia dysenterica DC.): desenvolvimento, caracterização microbiológica, sensorial, química e estudo da estabilidade. Boletim do Centro de Pesquisa de Processamento de Alimentos, 31 (1), 125-138. http://dx.doi.org/10.5380/cep.v31i1.32709

Brasil. Ministério da Agricultura, Pecuária e Abastecimento. Instrução Normativa n ${ }^{\circ} 12$ de 04 de setembro de 2003 . Aprova o Regulamento Técnico para Fixação dos Padrões de Identidade e Qualidade Gerais para Suco Tropical; os Padrões de Identidade e Qualidade dos Sucos Tropicais de Abacaxi, Acerola, Cajá, Caju, Goiaba, Graviola, Mamão, Manga, Mangaba, Maracujá e Pitanga; e os Padrões de Identidade e Qualidade dos Néctares de Abacaxi, Acerola, Cajá, Caju, Goiaba, Graviola, Mamão, Manga, Maracujá, Pêssego e Pitanga. Diário Oficial da União, Brasília, DF, 05 set. 2003.

Brasil. Ministério da Agricultura, Pecuária e Abastecimento. Instrução Normativa n ${ }^{\text {o }} 37$ de 01 de outubro de 2018. Estabelecer, na forma dos Anexos desta Instrução Normativa, os parâmetros analíticos de suco e de polpa de frutas e a listagem das frutas e demais quesitos complementares aos padrões de identidade e qualidade já fixados pelo Ministro da Agricultura, Pecuária e Abastecimento através da IN MAPA n 49 , de 26 de setembro de 2018 . Diário Oficial da União, Brasília, DF, 08 out. 2018.

Brasil. Presidência da República. Casa Civil. Decreto nº 6871 de 04 de junho de 2009 (2009). Regulamenta a Lei no 8.918 , de 14 de julho de 1994, que dispõe sobre a padronização, a classificação, o registro, a inspeção, a produção e a fiscalização de bebidas. Diário Oficial da União, Brasília, DF, 04 jun. 2009. 
Caluwé, E., Halamova, K., \& Damme, P. V. (2010). Tamarindus indica L. - A review of traditional uses, phytochemistry and pharmacology. Afrika Focus, 23 (1), 53-83. https://doi.org/10.21825/af.v23i1.5039

Cândido, L. M. B., \& Campos, A. M. (1996). Alimentos para fins especiais: dietéticos. Livraria Varella.

Cardoso, L. M., Batista, A. G., Hamacek, F. R., Dias, P. A., Rosa, B. C., Dessimoni, P. V., \& Dessimoni-Pinto, N. A. V. (2012). Quality of pulp and jellies of tamarind. Alimentos e Nutrição, 23 (3), 355-360. http://serv-bib.fcfar.unesp.br/seer/index.php/alimentos/article/view/355/1842

Deliza, R. (2001). The use of "ideal point" scale to determine the best sugar and dilution levels of passion fruit juice by consumers. Alimentaria, 38 (324), 109113.

Ferreira, V. L. P., Almeida, T. C. A. de, Pettinelli, M. L. C. de V., Silva, M. A. A. P. da, Chaves, J. B. P., \& Barbosa, E. M. de M. (2000). Análise sensorial: testes discriminativos e afetivos. Profíqua, p. $54-71$.

Flora do Brasil. (2019). Fabaceae in Flora do Brasil 2020 em construção. Rio de Janeiro: Jardim Botânico do Rio de Janeiro. http://floradobrasil.jbrj.gov.br/reflora/floradobrasil/FB23201

Freitas, M. L. F. (2013). Néctar de pitanga preparado com diferentes edulcorantes: determinação do perfil sensorial e estudos com consumidores. $141 \mathrm{f}$. Dissertação (Mestrado em Alimentos e Nutrição) - Universidade Estadual de Campinas, Faculdade de Engenharia de Alimentos, Campinas, SP, Brasil.

Instituto Adolfo Lutz - IAL. (2008). Métodos físico-químicos para análise de alimentos. (4a ed.), Ministério da Saúde.

Macfie, H. J. H., Bratchell, N., Greenhoff, K., \& Vallis, L. V. (1989). Designs to balance the effect of order of presentation and first-order carry-over effects in hall tests. Journal of Sensory Studies, 4 (2), 129-148. https://doi.org/10.1111/j.1745-459X.1989.tb00463.x

Maeda, R. N., Pantoja, L., Yuyama, L. K. O., \& Chaar, J. M. (2006). Determinação da formulação e caracterização do néctar de camu-camu (Myrciaria dubia McVaugh). Ciência e Tecnologia de Alimentos, 26 (1), 70-74. https://doi.org/10.1590/S0101-20612006000100012

Maia, M. C. A., Galvão, A. P. G. L. K., Della Modesta, R. C., \& Pereira Junior, N. (2008). Avaliação sensorial de sorvetes à base de xilitol. Ciência e Tecnologia de Alimentos, 28 (1), 146-151. https://www.scielo.br/pdf/cta/v28n1/20.pdf

Pereira, A. S., Shitsuka, D. M., Parreira, F. J., \& Shitsuka, R. (2018). Metodologia da pesquisa científica. UAB/NTE/UFSM. https://repositorio.ufsm.br/bitstream/handle/1/15824/Lic_Computacao_Metodologia-Pesquisa-Cientifica.pdf?sequence=1.

Schiassi, M. C. E. V., Souza, V. R. D., Lago, A. M. T., Campos, L. G., \& Queiroz, F. (2018). Fruits from the Brazilian Cerrado region: Physico-chemical characterization, bioactive compounds, antioxidant activities, and sensory evaluation. Food Chemistry, 245, 305-311. https://doi.org/10.1016/j.foodchem.2017.10.104

Silva, T. E., Silva, T. E.,Santos, L. S. dos, Garcia, L. G. C., \& Santos, P. A. dos. (2020). Iogurte grego com adição de polpa de tamarindo: aspectos físicos, químicos, microbiológicos e sensoriais. Research, Society and Development, 9 (7), e896974065. http://dx.doi.org/10.33448/rsd-v9i7.4065

Souza, V. F., Silva, K. R. R., Bezerra, N. M., \& Nézio, E. P. X. (2019). Elaboração e caracterização físico-química de néctar de tamarindo (Tamarindus indica L.). In: V ENCONTRO NACIONAL DA AGROINDÚSTRIA, Bananeiras. Anais eletrônicos... Campinas, Galoá, 2020. https://proceedings.science/enag/enag-2019/papers/elaboracao-e-caracterizacao-fisico-quimica-de-nectar-de-tamarindo--tamarindus-indica-l--

Tabela brasileira de composição de alimentos - TACO. (2011). (4a ed.), Campinas: NEPA- UNICAMP. http://www.nepa.unicamp.br/taco/contar/taco_4_edicao_ampliada_e_revisada.pdf?arquivo=taco_4_versao_ampliada_e_revisada.pdf

Teixeira, N. de C. (2011). Desenvolvimento, caracterização físico-química e avaliação sensorial de suco de jabuticaba (Myrciaria Jaboticaba (Vell) Berg). 139 f. Dissertação (Mestrado em Ciências de Alimentos) - Faculdade de Farmácia da Universidade Federal de Minas Gerais, Belo Horizonte, MG, Brasil.

Yuyama, L. K. O., Pantoja, L., Maeda, R. N., Aguiar, J. P. L., \& Silva, S. B. (2008). Desenvolvimento e aceitabilidade de geléia dietética de cubiu (Solanum sessiliflorum Dunal). Ciência e Tecnologia de Alimentos, 28 (4), 929-934. https://www.scielo.br/pdf/cta/v28n4/a26v28n4.pdf

Zacharis, C. (2012). Xylitol. In O'Donnell, K., Kearsley, M. W. (Org.), Sweeteners and Sugar Alternatives in Food Technology (pp 347-377). Oxford, UK: John Wiley and Sons Ltda. 